\title{
Treatment of Giant Fibroadenoma in Young Women: Results after Tumor Excision without Reconstructive Surgery
}

\section{Therapie von mammären Riesenfibroadenomen bei jungen Frauen: Klinische Ergebnisse nach einfacher Enukleation}

Authors

Affiliations
U. Hille-Betz ${ }^{1}$, R. Klapdor ${ }^{1}$, H. Henseler ${ }^{2}$, P. Soergel ${ }^{1}$, F. Länger $^{3}$

${ }^{1}$ Frauenklinik, Medizinische Hochschule Hannover, Hannover

${ }^{2}$ Klinik für Plastische Chirurgie, Medizinische Hochschule Hannover, Hannover

3 Institut für Pathologie, Medizinische Hochschule Hannover, Hannover

\section{Key words}

- fibroadenoma

- giant fibroadenoma

- breast asymmetry

Schlüsselwörter

- Fibroadenome

- Riesenfibroadenome

- Mammaasymmetrie

Deutsche Version unter: www.thieme-connect.de/ ejournals/gebfra

$\begin{array}{ll}\text { received } & 28.1 .2015 \\ \text { revised } & 17.3 .2015 \\ \text { accepted } & 19.4 .2015\end{array}$

Bibliography

DOI http://dx.doi.org/

10.1055/s-0035-1546108

Geburtsh Frauenheilk 2015; 75 :

929-934 ๑ Georg Thieme

Verlag KG Stuttgart · New York ISSN 0016-5751

\section{Correspondence}

Dr. med. Ursula Hille-Betz

Klinik für Frauenheilkunde und Geburtshilfe

Medizinische Hochschule

Hannover

Carl-Neuberg-Straße 1

30625 Hannover

hille-betz.ursula@

mh-hannover.de

\section{Abstract}

$\nabla$

Introduction: Giant fibroadenoma (GFA) of the breast is defined as fibroadenoma larger than $5 \mathrm{~cm}$, usually presenting unilaterally and manifesting as breast asymmetry or deformity of the breast.

Material and Methods: A retrospective database search was done of all patients with giant fibroadenoma who underwent surgery for GFA in the breast center of Hanover Medical School between 2007 and 2014; all patients with GFA were followed up. Data were analyzed with regard to tumor and patient characteristics and esthetic outcome.

Results: A total of 13 patients with symptomatic GFA underwent surgery between 2007 and 2014. Mean patient age was 21.2 years (range 14-31 years). In 8 of 13 patients the tumor had resulted in breast deformity and/or breast asymmetry. Average size of the mass was $10.2 \mathrm{~cm}$ (range 8.5$12 \mathrm{~cm}$ ) and average weight was $203.6 \mathrm{~g}$ (range 151.2-323.5 g). Initial clinical suspicion of GFA was confirmed by ultrasound examination. Preoperative core biopsy revealed fibroadenoma in 8/13 cases, cellular fibroepithelial lesions with a differential diagnosis of benign phyllodes tumor in 3 cases and unspecific histological findings in the remaining 2 cases.

Conclusion: Excision was done using an inframammary or periareolar approach without reconstructive plasty. The cosmetic results were good, as were the outcomes on follow-up. We therefore favor this surgical technique to treat giant fibroadenoma of similar size to those described above.

\section{Zusammenfassung \\ $\nabla$}

Einleitung: Riesenfibroadenome (RFA) der Mamma sind durch eine Größe von mehr als $5 \mathrm{~cm}$ definiert und zeichnen sich klinisch durch eine meist einseitige Lokalisation mit belastender Seitenasymmetrie oder Deformität der Brust aus.

Material und Methoden: Retrospektive Datenbanksuche aller zwischen 2007 und 2014 behandelten Patientinnen mit Riesenfibroadenomen im Brustzentrum der Medizinischen Hochschule Hannover, gefolgt von gezielten Nachuntersuchung aller Patientinnen. Auswertung im Hinblick auf Charakteristika des Tumors sowie der Patientin und des ästhetischen Outcomes.

Ergebnisse: Es wurden im obengenannten Zeitraum 13 Patientinnen mit einem Durchschnittsalter von 21,2 Jahren (Spannweite 14-31 Jahre) behandelt, die ein symptomatisches RFA aufwiesen. Bei 8/13 Patientinnen lag klinisch eine Deformität der Brust und/oder Asymmetrie der Brüste vor. Die Durchschnittsgröße der RFA, die eine Asymmetrie verursachten, lag bei $10,2 \mathrm{~cm}$ (Spannweite $8,5-12 \mathrm{~cm}$ ) bei einem Durchschnittsgewicht von 203,6 g (Spannweite 151,2$323,5 \mathrm{~g})$. Die klinische Verdachtsdiagnose eines RFA wurde zunächst sonografisch gestellt, die bioptische präoperative Abklärung ergab in 8/13 Fällen Befunde im Sinne eines Fibroadenoms, in 3 Fällen zellreiche fibroepitheliale Neoplasien mit der Differenzialdiagnose eines benignen Phylloidestumors und unspezifische Befunde in 2 weiteren Fällen.

Schlussfolgerung: Exzisionen über einen Submammär- oder Perimamillärschnitt ohne Einsatz einer plastischen Operationstechnik erwiesen sich als kosmetisch günstig und zeigten gute Ergebnisse in der Nachuntersuchung, weshalb wir diese Technik bei Riesenfibroadenomen der angegebenen Größenordnung favorisieren. 


\section{Introduction}

$\nabla$

Fibroadenomas are typically found in women in the 2nd and 3rd decade of life. The prevalence in this age group has been estimated as $2.2 \%$ [1]. Giant fibroadenomas (GFAs) larger than $5 \mathrm{~cm}$ typically occur in young women [2]. The most important morphological findings for this clinical picture are conventional, cellular or juvenile fibroadenoma and phyllodes tumors; it is important to differentiate between these tumors preoperatively because of the different therapeutic approach required.

The diagnosis and treatment of giant fibroadenoma can be a challenge for the treating physicians. As fibroadenoma is considered a benign lesion without a tendency to malignant degeneration, surgical treatment is generally not considered necessary to treat fibroadenoma. However, because of their size so-called giant fibroadenomas can lead to local problems including breast asymmetry or breast deformity. It can become a cosmetic problem for the affected patient with serious psychological effects. In our experience, the following problems may arise in the management of these lesions: diagnosis of fibroadenoma using core-needle biopsy can be difficult as it is not always possible to differentiate between cellular fibroadenoma, phyllodes tumor and unspecific findings based on the biopsy sample $[3,4]$. This can lead to some uncertainty whether surgical intervention is appropriate and if so, which type of surgical treatment would be best. This, in turn, can lead to delays in treatment. Affected patients are often extremely concerned about the potential cosmetic changes to the appearance of the breast after surgery and may be unsure whether primary surgery should include some form of corrective plastic surgery. The literature gives few systematic recommendations on the surgical treatment of rare giant fibroadenomas, and some of the recommendations are contradictory: potential treatments range from simple excision by more cosmetically appealing incisions (inframammary fold, areolar incision) $[5,6]$ to reduction mammaplasty or even mastectomy with reconstruction $[7,8]$. This study aims to evaluate the excision of fibroadenomas using a periareolar or inframammary approach without simultaneous plastic reconstruction based on an analysis of our extensive patient population.

\section{Material and Methods}

$\nabla$

\section{Identification of patients}

The data of patients treated in the gynecological department of Hanover Medical School between 2007 and 2014 was retrospectively analyzed. The data of patients with a benign lesion of the breast larger than $5 \mathrm{~cm}$ who underwent surgical excision with a final diagnosis of fibroadenoma of the breast were included in our analysis. Data were obtained by carrying out a database search of our documentation program Viewpoint PIA (GE Healthcare). The data obtained were then matched with data from the database of the Pathology Department (SAP system). Data on patients, surgical procedures and histology were additionally obtained from the electronic medical files (SAP system).

\section{Description of local standard of care}

Histological work-up of findings by core-needle biopsy was done preoperatively in all cases identified as giant fibroadenoma. All surgical procedures were carried out by gynecologists specialized in breast surgery (breast surgeon/senior breast surgeon certified by the German Cancer Society). Excision was done using either a periareolar or an inframammary approach, depending on the localization of the mass. The standard procedure carried out in all patients of the cohort consisted of simple enucleation of the tumor without plastic reconstruction. Large-scale subcutaneous adaptation was not done.

\section{Statistical analysis}

Analysis included age, ultrasound findings at diagnosis, preoperative and postoperative histological findings, surgical method, operating times, complications, duration of hospital stay, the esthetic appearance of the breast, both preoperatively and postoperatively, and standardized photographs. Descriptive analysis was done of the above-listed variables. Statistical analysis was carried out using Excel 2010 (Microsoft Corporation, Redmond, WA, USA).

\section{Results \\ $\boldsymbol{\nabla}$}

Patients

Thirteen patients with a mean age of 21.2 years (range 14-31) were included in the analysis. On ultrasound, the tumors presented as circumscribed, homogeneous, oval and hypoechogenic masses, with some presenting as strongly lobulated masses typi-

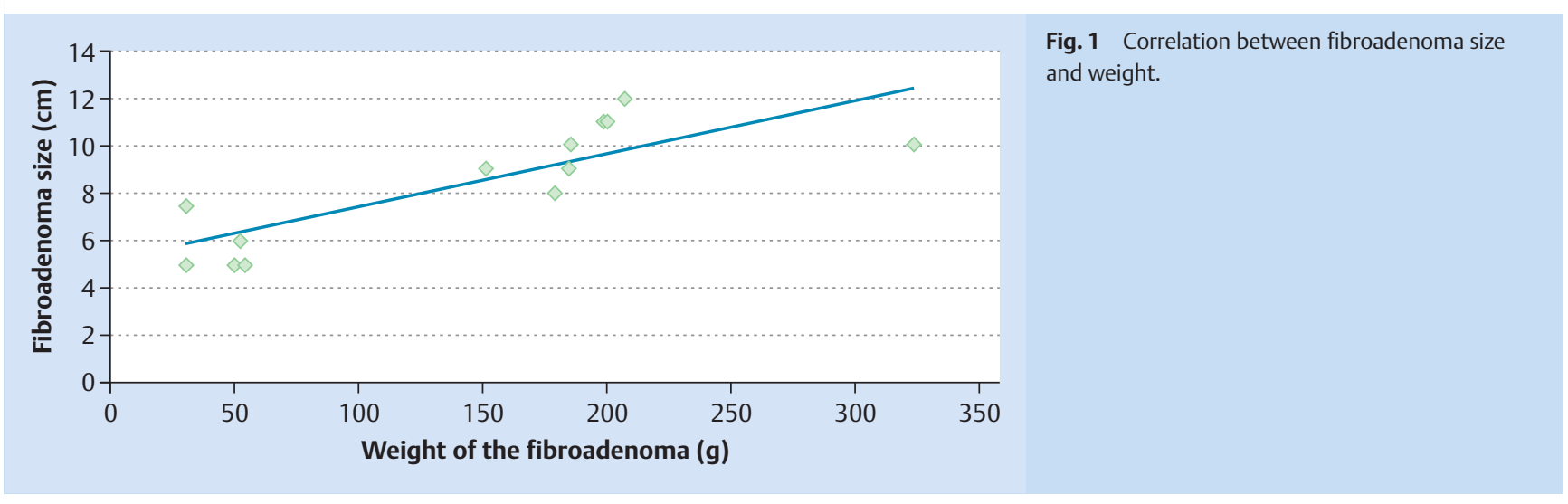



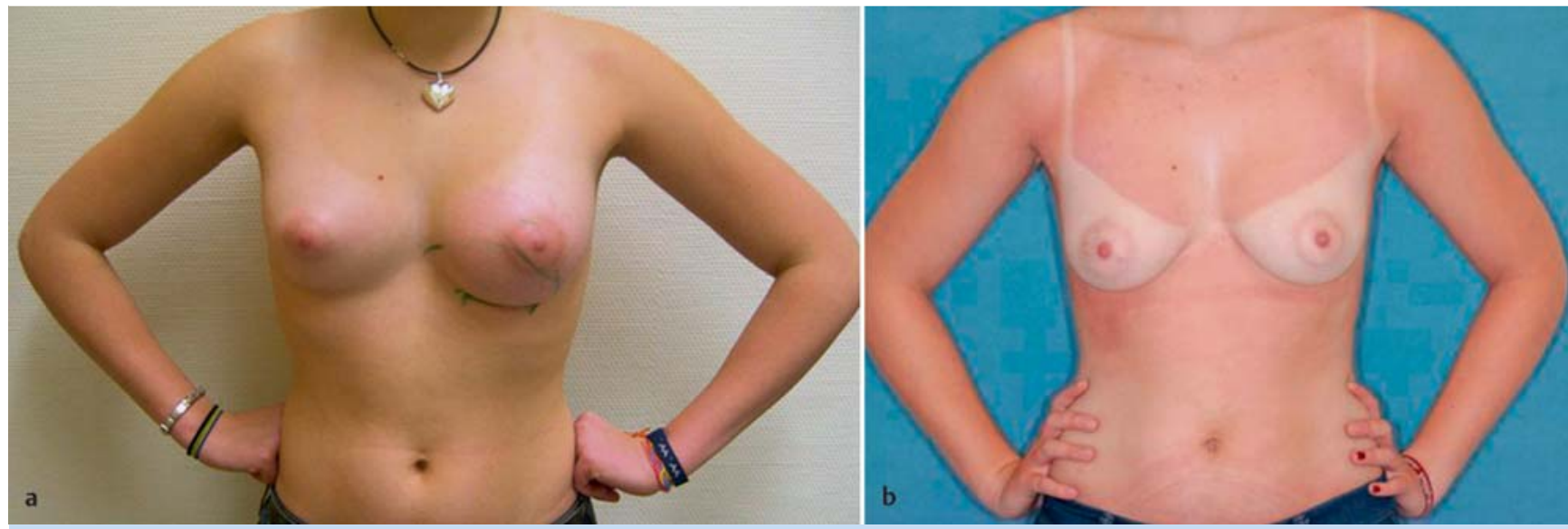

Fig. $\mathbf{2} \mathbf{a}$ and $\mathbf{b}$ a Preoperative photograph of a patient aged 16 years. The patient presents with marked left-sided breast asymmetry. The extent of marked on the patient's skin. $\mathbf{b}$ The same patient aged 19 years with symthe mass and the planned incision along the inframammary fold have been

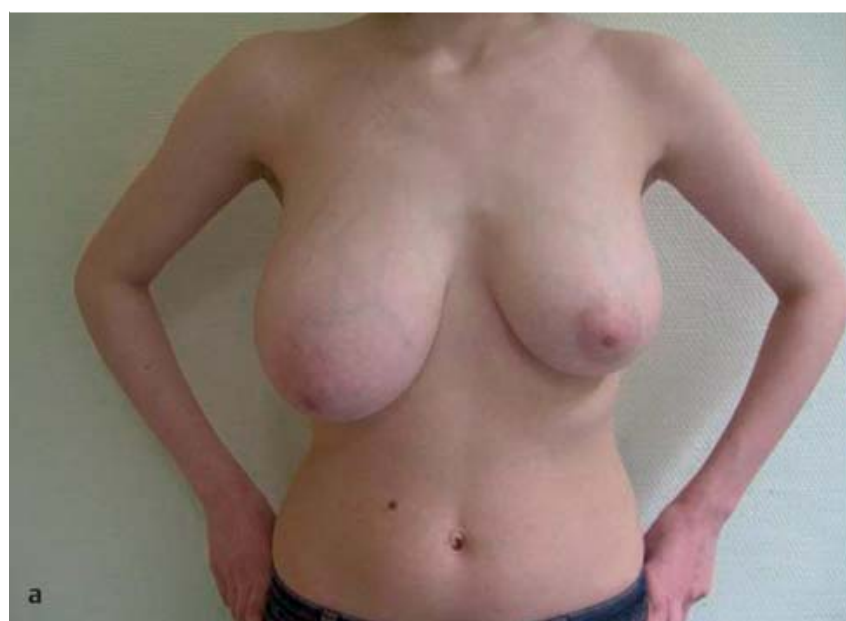

Fig. $\mathbf{3} \mathbf{a}$ and $\mathbf{b}$ a Preoperative photograph of a patient aged 18 years with a $10 \mathrm{~cm}$ fibroadenoma occupying the cranial quadrant. $\mathbf{b}$ The same patient photographed 3 years and 2 months postoperatively after resection of a fi-

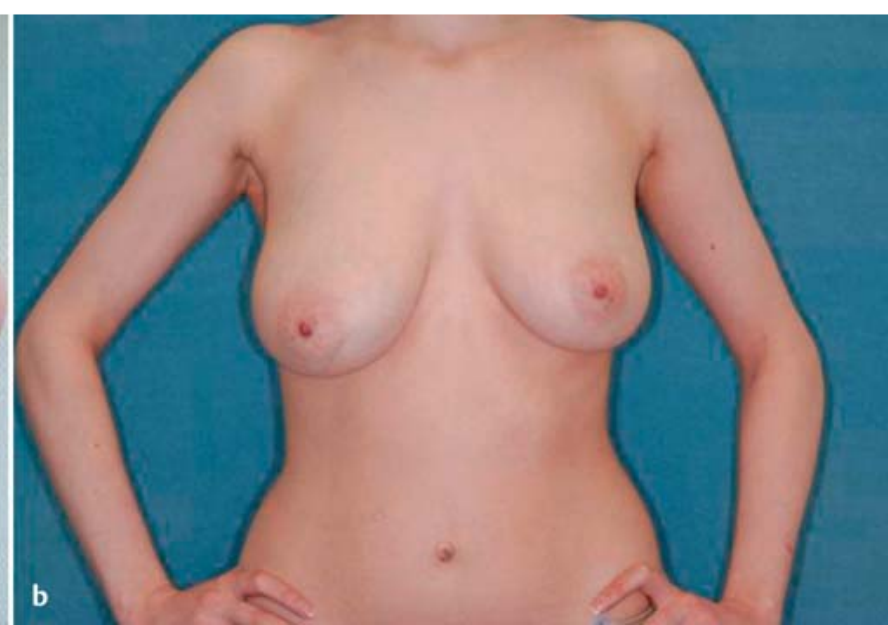

broadenoma weighing $323 \mathrm{~g}$. Minimal breast asymmetry is present but the patient is extremely satisfied with the result. cal for fibroadenoma. Preoperative histological classification of the tumors as fibroadenoma was possible in 8/13 (62\%) cases. Individual tumor classifications were fibroadenoma or fibroadenomatoid mastopathy in 8 cases, cellular fibroepithelial neoplasia with a differential diagnosis of benign phyllodes tumor in 3 cases, 1 case with unspecific parenchymal fibrosis and 1 case of pseudoangiomatous stromal hyperplasia.

\section{Treatment}

Six of 13 (46.2\%) fibroadenomas located in the upper quadrant were excised using an areolar approach. Seven of 13 (53.8\%) fibroadenomas were excised using an inframammary approach. Of these 7 cases, 2 were located in the upper quadrants. There were no intraoperative or postoperative complications such as secondary bleeding or wound healing disorders. The mean operating time was 32.3 (range: 21-61) minutes. Mean duration of hospital stay was 2.2 (range: $1-5$ ) days.
Postoperative histological findings and esthetic results Mean weight of fibroadenomas with diameters of up to $7.5 \mathrm{~cm} \mathrm{(4/}$ $13 ; 30.8 \%$ ) was $43.2 \mathrm{~g}$. The mean weight of tumors with diameters between 8 and a maximum of $11 \mathrm{~cm}$ was $203.6 \mathrm{~g}$. $\odot$ Fig. 1 shows the correlation between tumor size and weight.

Eight of $13(61.5 \%)$ patients presented preoperatively with marked deformation of the breast and bilateral asymmetry. None of the patients still presented with deformation or significant bilateral breast asymmetry at follow-up (mean postoperative follow-up: 45 [range 3-118] months).

- Fig. 2 a shows a patient aged 16 years with a giant juvenile fibroadenoma weighing $184 \mathrm{~g}$ (diameter: $9 \mathrm{~cm}$ ) occupying the entire lower inner quadrant and extending to the retromamillary region. The rapid growth of the mass led to the formation of striae on the breast. The mass was excised via an inframammary incision. Fig. $\mathbf{2}$ b shows the same patient aged 19 years with completely symmetrical breasts. The scar is barely visible even when the patient lifts her arms. 


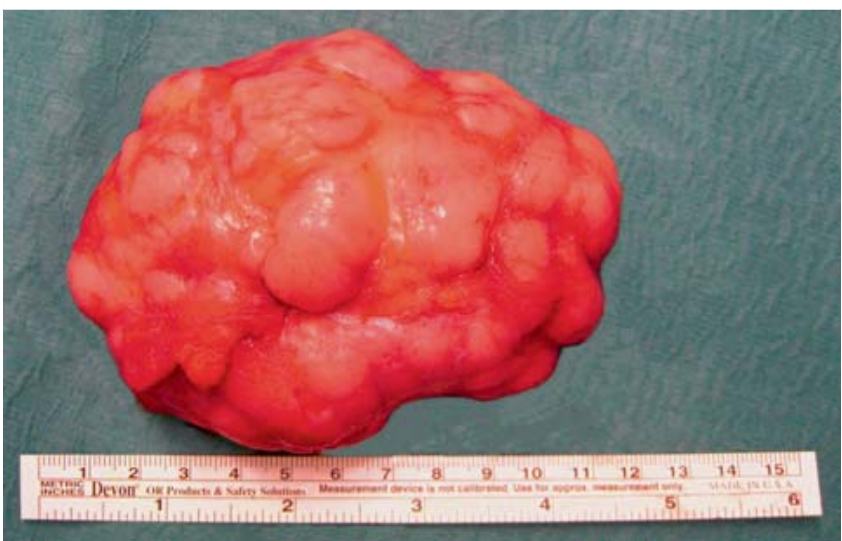

Fig. 4 Macroscopic findings of fibroadenoma for the patient shown in O Fig. 3.

The patient shown in 0 Fig. 3 a presented with pronounced breast asymmetry due to a giant fibroadenoma ( $323 \mathrm{~g}$; diameter: $10 \mathrm{~cm}$ ) which occupied the cranial quadrant of the right breast. Prior to presentation to our hospital the patient attended an external consultation, in consequence of which she asked for simultaneous reduction mammaplasty. We opted to excise the mass ( Fig. 4) using a cranial periareolar incision. Fig. 3 b, taken at 3 years and 2 months, shows successful breast reduction and skin recovery with only minimal asymmetry. This result was already evident at follow-up 4 weeks postoperatively.

Ultrasound examination of a patient with a small firm breast ( $B$ cup) found almost no healthy breast tissue $(1 \mathrm{~cm})$ as it had been largely displaced by a giant fibroadenoma. On inspection, the giant fibroadenoma resulted in only minimal breast asymmetry ( Fig. 5a). The patient presented to us for a second opinion as she had been advised to either undergo simultaneous augmentation or to abstain from excising the fibroadenoma, as it was thought that excision of the mass would otherwise result in breast disfigurement because of the loss of volume. Fig. 5 a shows the patient preoperatively with a $10 \times 9 \mathrm{~cm}$ fibroadenoma occupying all quadrants. We carried out simple excision of the fi- broadenoma, which weighed $185 \mathrm{~g}$, through an inframammary fold incision and achieved a symmetrical result ( $\mathbf{F i g}$. $\mathbf{5}$ b).

\section{Discussion}

$\nabla$

Biopsy diagnosis of fibroepithelial neoplasia is made more difficult by three specific morphological features; our case series presented here include an example of each of these specific morphological characteristics. With fibroadenomas and particularly with giant fibroadenomas, regressive changes can lead to false-negative findings on biopsy. The regressive changes can take the form of areas of non-specific hyalinization. If core biopsy only samples such hyalinization areas, it may be impossible to diagnose fibroadenoma (1 case in our series, which corresponds to $8 \%$ ). Secondary stromal changes which take the form of pseudoangiomatous stromal hyperplasia (PASH) may be present in fibroadenomas to such an extent that the characteristic architecture of the fibroadenoma cannot be detected in the biopsy sample ( 1 case in our series, which corresponds to $8 \%$ ). Morphological overlap can make it difficult to differentiate fibroadenoma from phyllodes tumor, particularly in the case of cellular fibroadenoma in a younger patient ( 3 cases in our series, which corresponds to $23 \%$ ) $[3,4,9,10]$. Additional immunohistochemical and molecular biological investigations will not usually lead to better selectivity, although they can be useful to differentiate malignant phyllodes tumors and tumors of intermediate malignancy from fibroadenoma [9, 10]. According to the current state of knowledge, the surgical management of benign phyllodes tumor does not require extensive resection; conservative surgical management may therefore be sufficient for benign phyllodes tumor [11].

The surgical management of giant fibroadenoma is still a matter of controversial debate in the literature. The necessity for excision is not disputed in patients presenting with breast deformity or suffering from local problems such as venous congestion, pressure necrosis and even occasionally ulceration [12].

While some authors recommend reduction mammaplasty with an inverted T-incision technique to resect large fibroadenomas, others recommend using a more cosmetically appealing incision $[5,6]$.

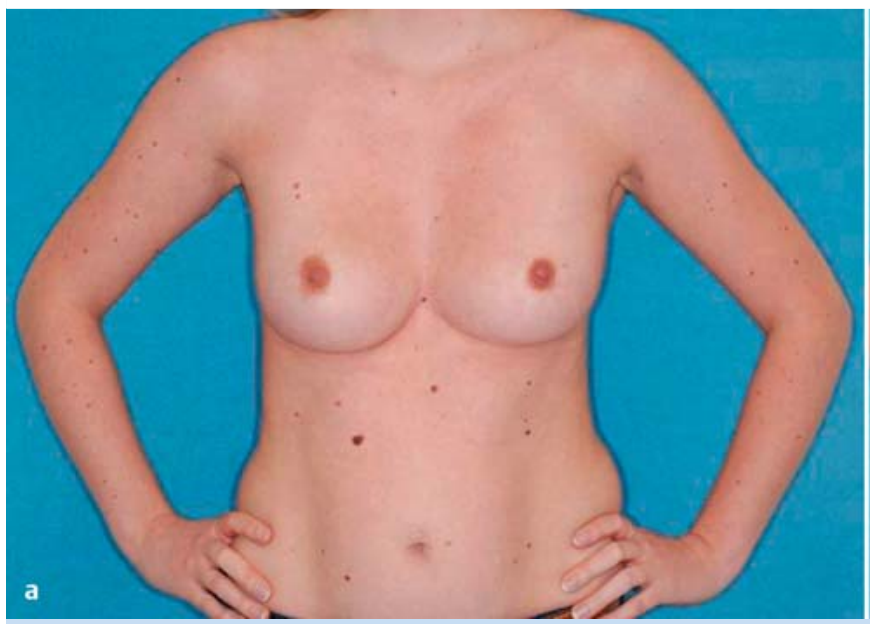

Fig. $5 \mathbf{a}$ and $\mathbf{b}$ a Patient with right-sided fibroadenoma but only slight breast asymmetry. The normal breast parenchyma was so strongly compressed by the mass that the breast appeared to be entirely occupied by the

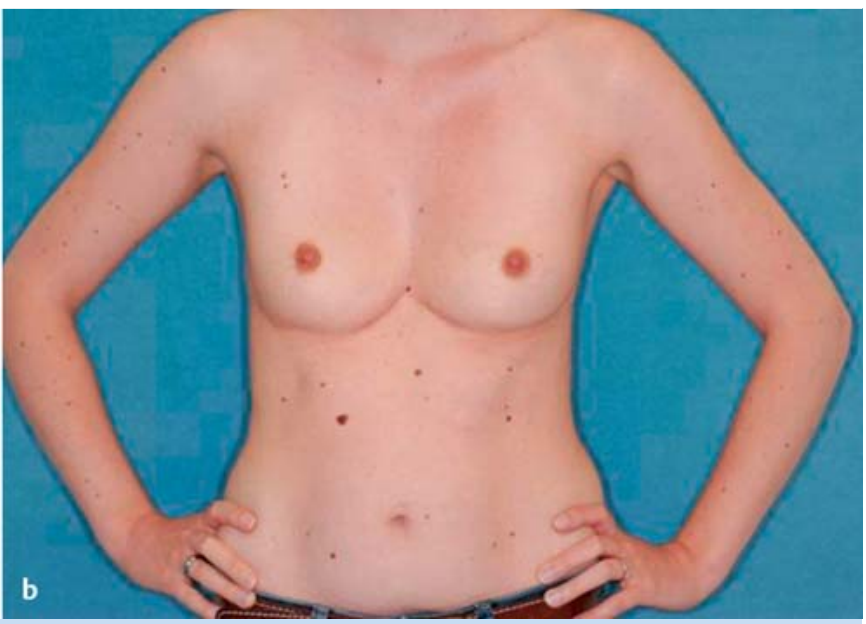

fibroadenoma. b A good result at 16 months after resection of a right-sided fibroadenoma weighing $185 \mathrm{~g}$ using an inframammary approach. 
Park and colleagues assessed the treatment of 9 patients with breast asymmetry due to giant fibroadenoma. Simple excision was performed in 2 patients. The remaining patients either had mastopexy or reduction mammaplasty using the inverted T-incision technique. The aim of this surgical technique is to reduce the amount of excess skin and immediately re-establish breast symmetry [12]. But this approach results in longer, and often more conspicuous, scarring as well as the typical risks associated with reduction mammaplasty/mastopexy. Yamamoto and Sugihara also carried out reduction mammaplasty in 2 patients with benign tumors of the breast [13]. However, as neither of the last two cited studies included the sizes and weights of the excised fibroadenomas, it is difficult to compare their data with ours.

The largest fibroadenoma resected in our patient cohort weighed $323 \mathrm{~g}$. There are a few reports in the literature on unusually large giant fibroadenomas excised during reduction mammaplasty. Chang and McGrath reported the resection of a fibroadenoma weighing $1550 \mathrm{~g}$ (diameter: $20 \mathrm{~cm}$ ) using the Mc Kissock reduction mammaplasty procedure. They pointed out that it is imperative to take the capacity of the skin to retract postoperatively into account when planning the procedure, as otherwise there is a risk of malposition of the nipple areola complex [2]. In a recently published study, Achebe and colleagues evaluated 27 patients who underwent reduction mammaplasty at the University of Nigeria Teaching Hospital for severe breast asymmetry caused by giant fibroadenoma. Average weight of fibroadenomas in these patients was $1500 \mathrm{~g}$ and average diameter was $15 \mathrm{~cm}$. The authors considered a difference in the position of the nipple areola complex of $6 \mathrm{~cm}$, i.e., significant breast asymmetry, to be a criterion for reduction mammoplasty [14]. In contrast we recorded good cosmetic results in terms of breast symmetry in our patient cohort after simple tumor enucleation without reduction mammaplasty. However it should be noted that the average tumor size in the African patient population was significantly larger compared to our patient cohort.

The literature on the surgical treatment of giant fibroadenoma also includes cases treated by mastectomy with immediate reconstruction of the breast. Dolmans et al. describe the case of a patient with giant fibroadenoma (diameter: $9 \times 9 \mathrm{~cm}$ ) treated by mastectomy and immediate breast reconstruction because of the unfavorable ratio of diseased tissue to healthy tissue on ultrasound [8]. By comparison, we report an excellent outcome in one of our patients with a similar presentation to the case described by Dolmans et al.. Our patient underwent simple tumor excision; the healthy breast parenchyma expanded completely subsequent to excision, resulting in breast symmetry ( Figs. 3 and 4).

In our study we showed that fibroadenomas weighing up to $323 \mathrm{~g}$ and with diameters of $8-12 \mathrm{~cm}$ can be treated by simple excision using a periareolar or inframammary incision. Outcomes at follow-up were cosmetically appealing and were associated with high levels of patient satisfaction. Our approach suggested itself because fibroadenoma is a benign tumor entity with tumor growth resulting in displacement and compression of adjacent breast tissue. After excision of the mass, re-expansion of breast tissue and skin retraction can be expected. Biggers et al. chose the same approach to treat 4 giant fibroadenomas with diameters ranging from 6 to $17 \mathrm{~cm}$ and also reported good postoperative breast symmetry on follow-up [5].

Gobbi et al. reported on 2 young patients who underwent excision of giant fibroadenoma (diameters: 8 and $10 \mathrm{~cm}$, respectively) using a periareolar approach. The outcome was satisfactory with regard to symmetry and cosmesis [15]. Other case studies also report good results after excision of a giant fibroadenoma weighing $350 \mathrm{~g}$ with a diameter of $12 \mathrm{~cm} \mathrm{[16]} \mathrm{and} \mathrm{of} \mathrm{a} \mathrm{giant} \mathrm{fibro-}$ adenoma weighing $300 \mathrm{~g}$ with a diameter of $14 \mathrm{~cm} \mathrm{[17].}$

Jacob reported a case of an unusually large fibroadenoma $(18 \times 12 \mathrm{~cm}, 2100 \mathrm{~g})$ which was removed by surgical excision without reduction mammaplasty to remove excess skin. Breast symmetry was found to be good on follow-up [6].

Possible complications of reduction mammaplasty or mastopexy such as wound healing disorders, reduced sensitivity or unsatisfactory cosmesis due to conspicuous scarring are well known.

No intraoperative or postoperative complications such as bleeding, secondary bleeding or wound healing disorders occurred in our patient cohort. The patients only remained in hospital for a short time and did not require lengthy convalescence. The results presented here emphasize the benefits of simple excision of giant fibroadenomas without reconstructive plastic surgery.

It is difficult to make a statement about the standard procedure to treat giant fibroadenoma, given the different sizes and shapes of breasts and the different tumor sizes and locations. When planning surgery it is important to remember that breast hyperplasia due to giant fibroadenoma is not real breast hyperplasia caused by excessive growth of the breast; the hyperplasia is caused by a benign tumor which leads to overexpansion of the skin with displacement and compression of normal breast tissue [6]. The results presented here show that awareness of this difference must influence surgical planning. Because of the minimal perioperative complications and the excellent esthetic outcome postoperatively, we recommend simple tumor excision to treat giant fibroadenomas with similar sizes to those we excised. Surgery should consist of a cosmetically unobtrusive incision without further plastic surgery, firming or reshaping of the breast.

\section{Conclusion}

Giant fibroadenomas like those described in our patient cohort can lead to marked breast deformity or asymmetry. We favor excision of the mass using a periareolar or inframammary incision and simple tumor enucleation without the use of plastic surgery as this offers good postoperative results.

\section{Conflict of Interest \\ $\nabla$}

None.

\section{References}

1 Santen RJ, Mansel R. Benign breast disorders. N Engl J Med 2005; 353 : 275-285

2 Chang DS, McGrath MH. Management of benign tumors of the adolescent breast. Plast Reconstr Surg 2007; 120: 13e-19e

3 Lawton TJ, Acs G, Argani P et al. Interobserver variability by pathologists in the distinction between cellular fibroadenomas and phyllodes tumors. Int J Surg Pathol 2014; 22: 695-698

4 Jara-Lazaro AR, Akhilesh M, Thike AA et al. Predictors of phyllodes tumours on core biopsy specimens of fibroepithelial neoplasms. Histopathology 2010; 57: 220-232

5 Biggers BD, Lamont JP, Etufugh CN et al. Inframammary approach for removal of giant juvenile fibroadenomas. J Am Coll Surg 2009; 208: e1e4

$6 \mathrm{Jacob}$ MM. Application of reduction mammaplasty in treatment of giant breast tumour. Br J Plast Surg 2000; 53: 265-266 
7 Poh MM, Ballard TN, Wendel JJ. Beckwith-Wiedemann syndrome and juvenile fibroadenoma: a case report. Ann Plast Surg 2010; 64: 803806

8 Dolmans GH, Hoogbergen MM, van Rappard JH. Giant fibroadenoma of one breast: immediate bilateral reconstruction. J Plast Reconstr Aesthet Surg 2007; 60: 1156-1157

9 Vilela MH, de Almeida FM, de Paula GM et al. Utility of Ki-67, CD10, CD34, p53, CD117, and mast cell content in the differential diagnosis of cellular fibroadenomas and in the classification of phyllodes tumors of the breast. Int J Surg Pathol 2014; 22: 485-491

10 Yang X, Kandil D, Cosar EF et al. Fibroepithelial tumors of the breast: pathologic and immunohistochemical features and molecular mechanisms. Arch Pathol Lab Med 2014; 138: 25-36

$11 \mathrm{Kim} \mathrm{S,} \mathrm{Kim} \mathrm{J,} \mathrm{Kim} \mathrm{DH} \mathrm{et} \mathrm{al.} \mathrm{Analysis} \mathrm{of} \mathrm{phyllodes} \mathrm{tumor} \mathrm{recurrence} \mathrm{ac-}$ cording to the histologic grade. Breast Cancer Res Treat 2013; 141: 353-363
12 Park CA, David LR, Argenta LC. Breast asymmetry: presentation of a giant fibroadenoma. Breast J 2006; 12: 451-461

13 Yamamoto $Y$, Sugihara $T$. Application of reduction mammaplasty in treatment of giant breast tumour. Br J Plast Surg 1998; 51: 109-112

14 Achebe JU, Njeze GE, Okwesili OR. Treatment of unilateral giant fibroadenoma by breast reduction skin incision: the inverted " $\mathrm{T}$ " technique. Niger J Clin Pract 2014; 17: 43-46

15 Gobbi D, Dall'Igna P, Alaggio R et al. Giant fibroadenoma of the breast in adolescents: report of 2 cases. J Pediatr Surg 2009; 44: e39-e41

16 Stehr KG, Lebeau A, Stehr M et al. Fibroadenoma of the breast in an 11year-old girl. Eur J Pediatr Surg 2004; 14: 56-59

17 Simmons RM, Cance WG, Iacicca MV. A giant juvenile fibroadenoma in a 12-year-old girl: a case for breast conservation. Breast J 2000; 6: 418420 